\title{
Access to Health Information. Editorial
}

\section{Kulikowski', A. Geissbuhler ${ }^{2}$}

'Department of Computer Science, Rutgers-The State University of New Jersey, New Brunswick, NJ, USA

2Department of Imaging and Medical Informatics, Geneva University Hospitals, Geneva, Switzerland

\begin{abstract}
Summary
Objectives: To provide an editorial introduction to the 2008 IMIA

Yearbook of Medical Informatics with an overview of its contents and contributors.

Methods: A brief overview of the main theme of "Access to Health Information", and an outline of the purposes, contents, format, and acknowledgment of contributions for the 2008 IMIA Yearbook.

Results: This 2008 issue of the IMIA Yearbook highlights how Access to Health Information has become ubiquitous over the web during the past decade, with a significant number of publications in biomedical and health informatics addressing both the science and technology of the field and how it is contributing to the improvement of health systems worldwide through a number of original contributions, and selected excellent papers published during the past 12 months.

Conclusion: The reviews and surveys on the main research fields in medical informatics in the Yearbook provide an overview of progress during this fortieth year of IMIA, focusing on the critical role that informatics plays in access to health information.
\end{abstract}

\section{Keywords}

Editorial, 2008 IMIA Yearbook of Medical Informatics, access to health information, surveys of biomedical informatics, reviews of biomedical informatics, history of biomedical informatics, IMIA and its societies

Geissbuhler A, Kulikowski C, editors. IMIA Yearbook of Medical Informatics 2008. Methods Inf Med 2008; 47 Suppl 1: 17-9
Introducing the 2008 Yearbook and its Theme on Access to Health Information

The International Medical Informatics Association (IMIA) Yearbook in 2008 focuses on the role of access to health information, which is critical to the contributions and impact of the field, just as IMIA completes the celebration of its fortieth birthday. The Yearbook starts with an article by the new President of IMIA, R. Haux entitled Health Care and Informatics: On IMIA's Opportunities and Responsibilities in its Fifth Decade. This editorial is followed by the Preface by A. Geissbuhler on the topic of access to health information as a key for better health in the knowledge society.

The Yearbook includes a number of major articles centered around the theme of Access to Health Information, covering present and past contributions of informatics to this topic, as well as future directions. The first, special section of the Yearbook on this topic carries a synopsis of the selected best papers by A. Gaudinat.

Original articles surveying topics within the specific subfields of medical informatics are an important component of the Yearbook. Section 1 on Health and Clinical Management has a survey by $\mathrm{H}$. F. Marin, et al. on Nursing Care Systems and a synopsis of the best selected articles by D. Kubias. Section 2 on $\mathrm{Hu}-$ man Factors includes an original survey article by G. Demiris et al. on Informatics for an Aging Society and a Synopsis of best selected papers in this subfield by $\mathrm{P}$. Ruch. Section 3 on Health Information Systems includes the original Survey article by P. J. Murray et al. entitled Towards Addressing the Opportunities and Challenges of Web 2.0 for Health and Informatics and the Synopsis by C. Bréant. Section 4 on Sensor, Signal and Imaging Informatics carries a survey by H. Müller on Medical Multimedia Retrieval 2.0 as well as his Synopsis on the best paper selection of the field. Section 5 on Decision Support, Knowledge Representation and Management includes the original survey article by $\mathrm{O}$. Bodenreider on Biomedical Ontologies in Action: Role in Knowledge Management, Data Integration and Decision Support and a Synopsis by A.-M. Rassinoux. Section 6 on Education and Consumer Informatics has an original Survey by L. Taylor et al. on E-Learning for Workforce Development and a Synopsis by C. Boyer. Section 7 on Bioinformatics includes a Survey by A. Burgun et al. on Accessing and Integrating Data and Knowledge for Biomedical Research and a Synopsis by Y. L. Yip.

The review section covers topics with impact in biomedical informatics, and includes articles by C. Lovis on Traceability in Healthcare: Crossing Boundaries, by S. M. Meystre, et al. on Extracting Information from Textual Documents in the Electronic Health Record: a Review of Recent Research, and by R. Meyer, et al. on Assessing the Capital Efficiency of Healthcare Information Technologies Investments: an econometric Perspective. 
Research and Education highlights programs in health and biomedical informatic around the globe, and this year includes summaries of programs from $\mathrm{M}$. Altwaijiri, et al. (King Saud bin Abdulaziz University for Health Sciences, Riyadh, Saudi Arabia), R. A. Greenes, et al. (Arizona State University, USA), and an article by W. Hersh on Health and Biomedical Informatics: Opportunities and Challenges for a Twenty-First Century Profession and its Education.

The section on the History of Medical Informatics includes an original paper surveying the very critical past 20 years on Rising Expectations: Access to Biomedical Information by Donald A. B. Lindberg and Betsy Humphreys of the National Library of Medicine, USA, while a paper on the history of nursing informatics is contributed by Marianne Talberg from Kuopio University, Finland, entitled: 25 Years in a Nutshell IMIA-NI, 1982 - 2007.

Jan van Bemmel, former IMIA President and Editor of the IMIA Yearbook presented an Award lecture at Medinfo 2007 in Brisbane on Reflections in Curiosity which is printed in this issue of the Yearbook.

\section{About the IMIA Yearbook of Medical Informatics}

The Yearbook of Medical Informatics of the International Medical Informatics Association (IMIA) is distributed through IMIA's Member and Corresponding Member Societies worldwide. Since its inception in 1992 it has been the single most important publication summarizing the activities of IMIA, and showcasing the best of medical informatics research for the previous year. Due to changing demands by its readership and the expanded availability of original papers over the web, the IMIA
Yearbook of Medical Informatics has adopted a new format and mode of publication since 2006, with the goal of substantially broadening its availability to virtually all members of the IMIA family. In particular, surveys, giving overviews of recent developments, and comprehensive introductory reviews on relevant topics in the different fields of health and biomedical informatics, have been added as original articles. Now published as a supplement of Methods of Information in Medicine, one of the official journals of IMIA, these original papers are peer-reviewed, indexed in Medline, and impact-factor listed. The Yearbook remains a nonprofit publication of IMIA, jointly published with Schattauer Verlag. It is currently subscribed to by 23 of IMIA's national member societies, providing access for about 20,000 individuals.

\section{Information on IMIA and on its Regional Groups}

As is the past, the IMIA Board and General Assembly met in conjunction with the MEDINFO 2007 Conference, held in Brisbane, Australia in August, and at the conclusion of the meeting leadership of the Association was transferred to the new President-elect Reinhold Haux (Germany) by Past President Nancy Lorenzi (USA). Because of his new duties, Professor Haux stepped down from editorship of the IMIA Yearbook, which is now edited by Antoine Geissbuhler (Switzerland) and Casimir Kulikowski (USA).

Peter Murray, the new IMIA Vice President for Working Groups, contributes an article on the IMIA Strategic Plan and how it is helping in coordinating the working group activities.

The Yearbook contains detailed information about IMIA, its Member Soci- eties, Regional Groups, Working Groups, and Special Interest Groups. Preparation of the general pages describing IMIA activities received considerable assistance from Steven Huesing, the Executive Director. The section on IMIA Working Groups and Special Interest Groups was greatly aided by contributions from Peter Murray. For the third time a more detailed report on the activities of IMIA regions is included with the help of Regional Editors. We would like to thank Arie Hasman and Rolf Engelbrecht (for EFMI), Ghislain B. Kouematchoua Tchuitcheu (for HELINA), Don Newsham and Tia Abner (for the North American IMIA Member Societies), Jack Li (for APAMI) and Alvaro Margolis (for IMIA LAC) for their valuable contributions. The IMIA representatives from the individual countries provided the material for their own national societies.

\section{Acknowledgments}

The editors gratefully acknowledge the contributions of the referees and guest editors. They would also like to thank the authors of the invited surveys, reviews and historic papers and the contributors to the Research and Education Section. They are most appreciative of the considerable skill, time, and effort devoted by the Managing Editors, especially the Executive Managing Editor Christian Lovis, and by the Section Managing Editors, Celia Boyer, Claudine Breant, Arnaud Gaudinat, Daniel Kubias, Henning Müller, Anne-Marie Rassinoux, Patrick Ruch, and Lina Yip. They especially wish to thank the Editorial Assistant, Martina Hutter, from the Medical Faculty at the University of Heidelberg, without whose untiring efforts the Yearbook would not have been completed. The editors also wish to thank the members of the Advisory Board for their in- 
valuable contributions to the planning of this Yearbook. They are: Marion Ball, IBM Center for Healthcare Management, Baltimore, MD, USA, Jan H. van Bemmel, Erasmus University Rotterdam, The Netherlands, and Alexa McCray, Harvard Medical School, Boston, USA.

The referees who contributed to the selection of articles in the 2008 Yearbook of Medical Informatics were:

Jos Aarts, The Netherlands

Hans Åhlfeldt, Sweden

Elske Ammenwerth, Austria

Sameer Antani, USA

Alan Aronson, USA

Robert Baud, Switzerland

Alex A.T. Bui, USA

Grace T.M. Dal Sasso, Brazil
Adrien Depeursinge, Switzerland

Thomas Deselaers, Germany

André Elisseeff, Switzerland

Gunter Eysenbach, Canada

Paul Fontelo, USA

Natalia Grabar, France

David Hawking, Australia

Ragnhild Helleso, Norway

Laurie Hoffman-Goetz, Canada

Michael Hogarth, USA

Josef Ingenerf, Germany

Marie-Christine Jaulent, France

Michel Joubert, France

Jayashree Kalpathy-Cramer, USA

Chen Li, Singapore

Daniel Luna, Argentina

Shuqian Luo, China

Yasushi Matsumura, Japan

Stéphane Meystre, USA
Peter Moorman, The Netherlands

Patricia Neafsey, USA

Michael Poprat, Germany

Rahil Qamar, UK

Daniel Racoceanu, Singapore

Elena Reale, Italy

Dietrich Rebholz-Schuhmann, UK

Miguel E. Ruiz, USA

Riccardo Serafin, Italy

Nicki Tiffin, South Africa

Thoralf Töpel, Germany

Manolis Tsiknakis, Greece

Anne-Lise Veuthey, Switzerland

Xiaohong Wang Gao, UK

Ulrich Woermann, Switzerland

Toru Yao, Japan

Q. Zeng, USA

Tatjana Zrimec, USA

Pierre Zweigenbaum, France

\section{Erratum}

The editors of the IMIA Yearbook want to inform their readers about the following facts: As stated in the editorial, the printing of the 2007 IMIA Yearbook was suppported by funding from Siemens Medical Solutions. Because no disclosure statement was included to cover potential conflicts of interest due to this circumstance that might have affected the original articles contained in the 2007 Yearbook we is- sue the following clarification. The authors of the original papers of the 2007 IMIA Yearbook of Medical Informatics Geissbuhler A, Haux R, Kulikowski C, editors. IMIA Yearbook of Medical Informatics 2007. Methods Inf Med 2007; 46 Suppl 1:1-250

herewith state that there is no conflict of interest and that they have received no external funding except for:

- Dr. S. Miksch: Fonds zur Förderung der wissenschaftlichen Forschung FWF (Austrian Science Fund), grant

\section{L290-N04}

- M.-C. Beuscart-Zéphir, P. Elkin, S. Pelayo, R. Beuscart: Research supported by FEDER and the Règion Nord-Pas de Calais (TAC EUCUE Project)

- R.A. Miller: Grant R01-LM007995 from the National Library of Medicine

- D.J. Severtson, L. Pape, C.D. Page, Jr., J.W. Shavlik, G.N. Phillips, Jr., P. Flatley Brennan: Grant No. T15LM007359 from the National Library of Medicine

\section{Editorial Retraction}

\section{Geissbuhler A, Haux R, Kulikowski, C.}

The author of the article

Mantas J. Education and Consumer Health Informatics In: Geissbuhler A, Haux R, Kulikowski C, editors. IMIA Yearbook of Medical Informatics 2007. Meth Inf Med 2007, 46 Suppl 1:90-4.

has verified that he used a substantial fragment of text without attributing it to Eysenbach G. Recent Advances: Consumer Health Informatics. BMJ 2000; 320:1713-16.
The author of the article including the unacknowledged material states that his failure to attribute was unintended and the resultof hurried completion of his paper. He extends his deepest apology to the author of the original text and the readers of the 2007 IMIA Yearbook for this plagiarism. The editors of the 2007 Yearbook apologize to the noncited author of the original article and to the readers of the IMIA Yearbook for not detecting and excluding this plagiarism from publication. They thank those who brought it to their attention.
It is the policy of the IMIA Yearbook that all articles comply with professional standards of publication to avoid plagiarism. This requires that only short fragments of text from original sources be quoted (enclosed in quotation marks) and be immediately followed by an accurate citation of the source from which the fragment was taken. Because the fragment in question was neither short nor cited for its origin, the author has asked that his paper be withdrawn, and the editors hereby publish this retraction. 